\title{
Motivating factors, potential deterrents and perceived physical impacts of blood donation on donors
}

\author{
Joseph S.E. ${ }^{1}$, Bose B.M. ${ }^{2}$, Joseph E. ${ }^{3}$, Poothiode U. ${ }^{4}$ \\ ${ }^{1}$ Serena Elizabeth Joseph, Medical student, ${ }^{2}$ Dr.Binu Mary Bose, Assistant Professor, Pathology, ${ }^{3}$ Dr.Elizabeth Joseph, \\ Professor, ${ }^{4}$ Dr.Usha Poothiode, Head of the department of Pathology, all authors are affiliated with MOSC Medical College, \\ Kolenchery, Kerala, India.
}

Corresponding Author: Dr. Binu Mary Bose, Assistant Professor, Pathology, MOSC Medical College, Kolenchery, Kerala, India. Email: doc_binubose@yahoo.co.in

\begin{abstract}
Background: Blood is a vital component of the human body, which constitute $7 \%$ of the body weight. To ensure an adequate supply of blood, it is necessary to make significant improvements in methods for recruiting and retaining donors and to increase their efficiency. This study was done to understand the factors that motivate and deter donors and also to assess the physical impacts perceived after blood donation. Materials and methods: A descriptive, cross-sectional study was conducted among voluntary donors coming to a blood bank using a self-administered questionnaire. The questionnaire contained sections pertaining to motivating factors, potential deterrents and perceived physical impacts of blood donation. Statistical analysis was performed using R-software. Results: The total number of donors were 113 out which of female donors comprise $5.3 \%$ and male donors $94.7 \%$. Altruism (73.1\%) and pain due to phlebotomy $(8.8 \%)$ was the strongest motivating and deterring factor respectively. Positive effects were perceived more than negative effects. Peer influence has a significant association with the level of education of the donors $\left(\mathrm{X}^{2}\right.$ test was performed and $\left.\mathrm{p}=0.03\right)$. As far as the occupation was considered availing leave was not a significant motivating factor $(\mathrm{p}<0.015)$. Social media hasn't significantly influenced the donors in considering their occupation and place of residence $(\mathrm{p}<0.0009, \mathrm{p}<0.0027)$. Conclusion: From the present study it can be inferred that the present awareness regarding blood donation through social media is inadequate. Thus, increased focus should be given on improving the awareness through social media.
\end{abstract}

Keywords: Blood, Donor, Deterrents, Motivating factors, Physical impacts

\section{Introduction}

Coping with the rising incidence of trauma cases, oncology, advanced surgical treatments and transplants, there is an ongoing need for blood donation, worldwide, to fulfill blood transfusion demands. WHO has estimates that India needs 12 million units of blood and its components annually. Each year the demand for blood increases by 2 $3 \%$ [1] and it is becoming increasingly difficult to recruit new blood donors. An understanding of the factors motivating and deterring donors of various age groups can facilitate more targeted recruitment and retention efforts by blood collection centers, thereby significantly expanding the existing donor pool $[2,3]$.

One important step towards improving the recruitment process is to clarify the importance of blood donation for society and at the same time describe in greater detail how donating blood affects the donor.

Manuscript received: $10^{\text {th }}$ November 2019

Reviewed: $20^{\text {th }}$ November 2019

Author Corrected: $25^{\text {th }}$ November 2019

Accepted for Publication: $30^{\text {th }}$ November 2019
The provision of a clear-cut picture of how accustomed donors perceive and experience blood donation [4] and decreasing the perception that there are health risks associated with donating blood may significantly contribute to an improvement in the recruitment of new donors [5].

In many studies conducted on voluntary donors across the world, prosocial beliefs [1-7] were the strongest motivating factors, regardless of age, sex, or ethnic background. They were altruism, (helpfulness), empathy (feeling for others) and social responsibility (a duty to help others) [3]. Other motivators were feeling of heroism, someone being proud of them and participation of friends or relatives [8]. Males responded more to altruistic factors, [8] and women, to motivation by friends and family [4]. Other studies $[3,9,10]$ found that satisfaction with current donation influenced the donor's intent to return. Thus, the strategy for keeping a donor base is three-fold: getting donors, keeping them happy and motivating them to return.

Pathology Update: Tropical Journal of Pathology \& Microbiology Available online at: www.medresearch.in 997 |P a g e 
The pain associated with donation was the most commonly rated potential deterrent $[4,6]$. In most of the studies, Nurses should be aware of the fear of phlebotomy and manage needle-associated anxiety [8]. Inconvenience and time constraints were significant in college-aged $[4,6]$ and older donors [11]. Males rated the time involved in blood donation as a deterrent more than women [8].

A majority of donors (54\%) were affected by blood donation of which $29 \%$ reported positive effects, such as satisfaction, while 19\% reported negative effects like dizziness, vertigo and by $6 \%$ reported mixed effects. Positive effects were long-lasting and negative effects transient [7].

\section{Objectives}

-To assess the frequency and percentage of various motivating factors, potential deterrents and perceived physical impacts of blood donation on donors

-To study the association of motivating factors, potential deterrents with various socio-demographic variables.

\section{Materials and Methods}

Study area: Blood bank of Malankara Orthodox Syrian Church Medical College, Kolenchery, Kerala, India.

Study design: A descriptive cross-sectional study.

Study population: Voluntary donors coming to the blood bank of Malankara Orthodox Syrian Church Medical College, Kolenchery, Kerala, India.

Inclusion criteria: All voluntary donors donating blood in the blood bank of a tertiary care hospital

Exclusion criteria: Replacement donors and deferred donors

Study sample: Sample size was calculated to be 113

Study duration: 2 months (April $1^{\text {st }}-M a y 31^{\text {st }} 2019$ )

Study method: Convenient sampling

Study Tool: 7-expert validated structured questionnaire

The expert validation was carried out by 7 experts, of which 4 were working in the tertiary care hospital in which the study was conducted and other 3 elsewhere. A pilot study using the same questionnaire was also conducted.
Data Collection Procedure: The data was collected using a 7-expert validated questionnaire from April $1^{\text {st }}$ to May $31^{\text {st }}$ 2019. The questionnaire comprised of 4 sections. In section A, questions regarding demographic data, the donor's age, gender, place of residence, occupation, education, number of times donated, desire for re-donation etc. were asked.

Section B was regarding the factors that motivate people to donate blood. There were 13 questions in this section which can be broadly divided into 5 domains - altruism, peer pressure, family influence, social media impact and personal reasons. The participants were asked to rate on a 5 -point scale. The first 3 responses were taken as negative and next 2 were regarded as positive. Section $\mathrm{C}$ was regarding the factors that deter the donors from donating blood in future. It consists of 9 questions which can be divided into 3 domains, physical, psychological and donor center related factors. The participants were asked to rate on a 5-point scale. The first 3 responses were taken as insignificant and next 2 were regarded as significant. Section $\mathrm{D}$ was regarding the physical effects perceived by the donors after blood donation, which can be classified as negative or positive effects. The responses were marked as yes or no.

Data Analysis: The results obtained and other details of analysis are given in section 5. Statistical analysis was performed using R-software. In this study, frequency and percentage for various motivating factors, potential deterrents and perceived physical impacts of blood donation on donors were assessed. The association of motivating factors, potential deterrents and perceived physical impacts with various socio-demographic variables was studied using Chi-square test/ Fischer's exact test. P value $<0.05$ was considered significant.

Ethical Consideration and Permission: The study was overseen and evaluated by the Institutional review board and Ethics committee of Malankara Orthodox Syrian Christian Church Medical College Hospital, Ernakulam, Kerala. Verbal and written informed consent was obtained and nature of study was explained to the participants before giving the questionnaire. The informed consent was separated from the questionnaire in order to maintain anonymity of the participants. The data was entered into Google forms.

\section{Results}

Descriptive studies: The total number of donors was 113, out which female donors comprise 5.3\% (6) and male donors $94.7 \%$ (107). 73 donors were in the age group of 18-30 years, 36 donors in the age group of 31-45 years and 4 donors, more than 45 years. $8 \%$ of the donors studied till twelfth grade, $27.4 \%$ completed twelfth grade and $64.6 \%$ had an education of degree or higher level. $66.4 \%$ of the donors were employed, $8 \%$ were unemployed and $25.7 \%$ were students. $15.9 \%$ were first time donors, $15.9 \%$ have donated once before, $26.5 \%$ have donated $2-5$ times before and $41.6 \%$ have donated more than five times previously.

Pathology Update: Tropical Journal of Pathology \& Microbiology Available online at: www.medresearch.in 998 |P a g e 
$85 \%$ expressed strong desire to donate blood again, $14 \%$ were somewhat likely to donate again and $1 \%$ were not sure about further donation.

Frequency and percentage of motivating factors, potential deterrents and perceived physical impacts of blood donation on donors

Frequency and percentage of motivating factors: Out of the 113 participants, $112(99 \%)$ agreed that donating blood is the right thing to do.

$104(92 \%)$ donated blood to serve the community or to help someone. Only $32(28.3 \%)$ were aware of the fact that there is a shortage of blood for people who need it. These three factors were grouped under the domain altruism and it was regarded as the strongest motivating factor (73.1\%). 93 (82.3\%) donated blood because their friends donated blood and $63(55.8 \%)$ donated because of influence from society. Therefore, social or peer influence was the second most important motivating factor (69\%). Family influence was also considered as an important motivating factor (55\%). Family influence included encouragement from a family member to donate blood (57.5\%), family being proud of his/her donating blood (60.2\%), family members setting a role model by donating blood $(40.7 \%)$

Personal reasons also served as motivating factors to donate blood (38\%) like to get a mini-physical examination done (31\%). It also included thoughts like donating blood is good for health $(79.5 \%)$ or that he/she may need blood someday (33.6\%) or for availing leave from college or workplace (4.4\%). Only $10 \%$ have rated social media influence as a motivating factor for donating blood.

Frequency and Percentage of Potential Deterrents: Personal reasons were regarded as potential deterrents for blood donation (3.83\%). These include pain due to phlebotomy (8.8\%), busy life (1.8\%) and physical discomfort after donation $(0.9 \%)$.

Psychological factors were the most influential deterrents for blood donation $(5.63 \%)$. These include fear of needles (8\%) or blood $(7.1 \%)$ and also concern about the potential negative impact on health $(1.8 \%)$.

Centre related factors were least rated deterrents $(2.1 \%)$ like inconvenient location $(2.7 \%)$ or timing of the donor centre $(0.9 \%)$ as well as the behaviour of the staff $(2.7 \%)$.

Frequency and percentage of perceived physical impacts: Physical impacts perceived after donation were either be positive or negative. The positive effects perceived included feeling better, satisfaction, relaxation and increased motivation for health. Out of 113 participants, $110(97.3 \%)$ experienced a feeling of satisfaction after blood donation, which was the most commonly perceived physical impact after donation, followed by effects like feeling better $9.7 \%$, relaxation $-93.8 \%$, and increased motivation for health-88.5\%. The negative effects were found to be less in comparison to the positive effects. The most common negative effect was thirst $(10 \%)$. The other negative effects include lethargy, diminished physical capacity, dizziness and headache

Association of motivating factors, potential deterrents with various socio-demographic variables.

Association of motivating factors with various socio-demographic variables: Motivating factors have no significant association with age, gender, number of times donated or intention for re-donation. Peer influence has a significant association with the level of education of the donors $\left(\mathrm{X}^{2}\right.$ test was performed and $\left.\mathrm{p}=0.03\right)$ as given in Table 1 .

As far as the occupation was considered availing leave was not a significant motivating factor as given in Table 2 . Social media hasn't significantly influenced the donors in considering their occupation and place of residence as given in Table 3.

Table-1: Association of motivating factors with various socio-demographic variables.

\begin{tabular}{|c|c|c|c|c|}
\hline \multirow{2}{*}{ Motivating Factors } & & \multicolumn{2}{|c|}{ Level of Education } & \multirow{2}{*}{ p-value } \\
\cline { 3 - 4 } & & Up to $\mathbf{1 2}^{\text {th }}$ Std & Higher & \multirow{2}{*}{0.043} \\
\hline \multirow{2}{*}{$\begin{array}{c}\text { My friends are } \\
\text { donating }\end{array}$} & Yes & 29 & 64 & 9 \\
\cline { 2 - 4 } & No & 11 & & \\
\hline
\end{tabular}

Pathology Update: Tropical Journal of Pathology \& Microbiology Available online at: www.medresearch.in 999 |P a g e 
Table-2: Association of motivating factors with various socio-demographic variables.

\begin{tabular}{|c|c|c|c|c|c|}
\hline \multirow{2}{*}{ Motivating Factors } & & \multicolumn{3}{|c|}{ Occupation } & \multirow{2}{*}{ p-value } \\
\cline { 3 - 5 } & & Student & Unemployed & Employed & 1 \\
\multirow{2}{*}{ To avail leave } & Yes & 4 & 0 & 74 & 0.015 \\
\cline { 2 - 5 } & No & 25 & 9 & 74 \\
\hline
\end{tabular}

Table-3: Association of motivating factors with various socio-demographic variables

\begin{tabular}{|c|c|c|c|c|c|c|c|c|}
\hline \multirow{2}{*}{$\begin{array}{c}\text { Motivating } \\
\text { Factors }\end{array}$} & & \multicolumn{3}{|c|}{ Occupation } & \multirow{2}{*}{$\begin{array}{c}\text { Place of } \\
\text { p- } \\
\text { Residence }\end{array}$} & \multicolumn{2}{|c|}{ p-value } \\
\cline { 3 - 9 } & & Student & Unemployed & Employed & Urban & Rural & p-value \\
\hline $\begin{array}{c}\text { In response } \\
\text { to the } \\
\text { campaign on } \\
\text { TV or radio }\end{array}$ & Yes & 7 & 0 & 4 & 0.009 & 6 & 5 & 0.027 \\
\cline { 2 - 9 } & No & 22 & 9 & 71 & & 24 & 78 & \\
\hline
\end{tabular}

Association of potential deterrents with various socio-demographic variables: The deterrents for blood donation does not have any significant association with age, gender, level of education, place of residence, occupation, no of times donated or intention for re-donation.

\section{Discussion}

Like most other studies [3,6] the present study also had a smaller number of female donors. In the study done in Chennai in 2013 also the male donors outnumbered females. Only very few studies $[12,13]$ showed an increased number of female donors, one of which was done in Spain, in the province of Huelva. Women were more inclined than men to give blood, because of altruistic reasons, with females contributing to most of the donors and first-time donors. According to that study, the most common restrictions to women giving blood, is low hemoglobin concentration, which reduce the number of female blood donations. Women also experience more difficulty when blood is withdrawn and are more prone to vasovagal reactions, which can negatively affect their experience as donors.

In the present study, most of the donors belonged to the age group 20-35 years, were highly educated and employed. This was also comparable with the study done in Chennai [14] in which most of the donors where between 18 and 25 years. Majority of them have donated more than five times and had a strong desire to donate again. Considering the motivating factors, altruism stands out as the driving force for blood donation regardless of age, sex, level of education or occupation compared to other studies [1-7].

In a cross-sectional study conducted in Sikkim, India in 2004 also, altruism was the primary reason among demographic groups to donate blood [15]. Very few donors have considered the shortage of blood as a reason to donate blood. This may be due to the lack of awareness that there is a shortage of blood for people who need it. Therefore, using the results of this study, the present study would like to highlight this issue and spread awareness about the necessity to donate blood. In contradiction to the present study, the study done in Chennai revealed that most of the people donated blood because they consider it as important life saving measure and they also thinks that there is a shortage of blood in blood banks [14]. The present study also showed that, most of the donors whether educated or not were significantly influenced by their peers. Family influence can also play a significant role in motivating the younger generation; parents can set an example for their kids to follow by donating blood. This is comparable to a study done in two blood banks in Delhi [16].

Surprisingly in the present study, availing leave was not a significant motivating factor for the donors, in contrast with many other studies. From this it can be understand that most of the donors don't consider using blood donation as an excuse for taking leave. In a study done in Greece, United states and Germany, incentives was considered an important motivating factor for blood donation which included availing of leave from work $[17,18,19]$.

Another aspect to be highlighted from the present study and a similar study done in Pune is that in contrast to what we expect social media hasn't significantly influenced the donors. Thus, it can be inferred that the present awareness regarding blood donation through social media is inadequate. Thus, increased focus should be given on improving the awareness through social media. One study has shown that social media is the second most common motivating factor for the first-time donors [19]. In accordance with other studies $[4,6,8]$, pain due to phlebotomy was rated the most common potential deterrent for future donation. Psychological reasons like fear of needles or blood also serve as deterrents. Previous studies [20-24] have cited inconvenient location and hours as

Pathology Update: Tropical Journal of Pathology \& Microbiology Available online at: www.medresearch.in 1000 |P a g e 
important barriers to donation for younger individuals [13], but in the present study, the results have proven that our blood bank is situated in an ideal location and the working hours are convenient for donors, as hardly few donors find the location, working hours and the behavior of the staff of the blood bank as a deterrent for donating blood. The present study also positive effects were perceived more than negative effects comparable with similar studies [7]. The majority of effects elicited by blood donation were positive like the feeling of satisfaction, feeling better, relaxation and increased motivation for health. The feeling of satisfaction was felt more than other effects by most of the donors $[3,9,10]$.

There was no association between frequency of occurrence of positive effects and the number of blood donation, indicating that there is no addictive relationship between donors and donations. The finding in this study of high frequency of occurrence of positive effects elicited in blood donors by blood donation may be of great importance in the recruitment of new blood donors. It can make blood donation less frightening and perhaps more attractive.

\section{Limitations}

The main limitations of the present study were the inadequate number of female donors and the study population of voluntary donors, which was not representative of the entire community.

\section{Conclusion}

Altruism and pain during phlebotomy where the most common motivating and deterrent factors among donors in our institution. The donors did not consider incentives and social media as motivating factors. Most of the donors felt very satisfied after donation and motivated to donate again.

\section{What the study adds to existing knowledge?}

From the present study it can be inferred that the present awareness regarding blood donation through social media is inadequate. Thus, increased focus should be given on improving the awareness through social media.

\section{Author's contribution}

Serena Elizabeth Joseph: Topic selection, data collection, analysis, preparation of article

Dr. Binu Mary Bose: Analysis, preparation of articles

Dr. Elizabeth Joseph: Topic selection, general guidance

Dr. Usha Poothiode: Guidance

\section{Acknowledgement}

Authors would like to thank Dr. Chithra Jayaprakash (Professor and HOD, Department of Microbiology, MOSC
Medical College, Kolenchery), Dr. Usha Poothiode (Professor and HOD, Department of Pathology, MOSC Medical College, Kolenchery), Dr. Anna Mathai (Professor, Department of Pathology, MOSC Medical College, Kolenchery), Dr. Sumit Dutta (Professor, Department of Community Medicine, MOSC Medical College, Kolenchery), Dr. Priyanka C.G (Consultant, Transfusion Medicine, Rajagiri Hospital, Aluva), Dr Sunitha Thomas (Senior Consultant, Pathology and Blood Bank Officer, Rajagiri Hospital, Aluva), Dr Divya. S. Deth, (Assistant Professor, Al-Azhar Medical College, Thodupuzha) for helping us in the validation of the questionnaire.

Authors would also like to thank the blood bank staff for helping in the data collection. Authors would like to express their sincere gratitude to Basil T. Baby (Medical student, MOSC Medical College, Kolenchery) for helping us with the data entry and Dr. Kalesh M Karun (Assistant Professor, Department of Biostatistics, MOSC Medical College, Kolenchery) who helped with the statistical analysis of this study.

Funding: No funding sources Conflict of interest: None declared

Ethical Approval: This study was approved by the Institutional Ethics Committee

\section{References}

1. Provan D. Better blood transfusion. BMJ. 1999;318 (7196):1435-1436. doi:10.1136/bmj.318.7196.1435.

2. Ferriman A. Decline in altruism threatens blood supplies. BMJ. 1998; 317:1405. https://doi.org/10.1136/bmj.317. 7170.1405 .

3. Yuan S, Hoffman M, Lu Q, Goldfinger D, Ziman A. Motivating factors and deterrents for blood donation among donors at a university campus-based collection center. Transfus. 2011;51(11):2438-2444. doi: 10.1111/j.15372995.2011.03174. x.

4. Gillespie TW, Hillyer CD. Blood donors and factors impacting the blood donation decision. Transfus Med Rev. 2002;16 (2): 115-130. https://doi.org/10.1053/tmrv.2002. 31461 .

5. Andaleeb SS, Basu AK. Explaining blood donation: the trust factor. J Health Care Mark. 1995;15(1):42-48.

6. Fink R, Ziman A, Hoffman M, Phan-tang M, Yuan S. Motivating factors and potential deterrents to Blood donation in high school aged Blood donors. J Blood Transfus. 2016;2016:8624230. doi: 10.1155/2016/ 8624230 . 
7. Nilsson Sojka B, Sojka P. The blood-donation experience: perceived physical, psychological and social impact of blood donation on the donors. Vox Sanguinis 2003;84(2):120-128. doi: https://doi.org/10.1046/j.14230410.2003.00271.x.

8. Glynn SA, Kleinman SH, Schreiber GB, Zuck T, Combs SM, Bethel J, et al. Retrovirus Epidemiology Donor Study. Motivations to donate blood: demographic comparisons. Transfus. 2002;42(2):216-25. doi: https://doi.org/10.1046/j. 1537-2995.2002.00008.x

9. Glynn SA, Schreiber GB, Murphy EL, Kessler D, Higgins $\mathrm{M}$, Wright DJ, et al. Factors influencing the decision to donate: racial and ethnic comparisons. Transfus. 2006;46(6):980-990. doi: 10.4103/ 0974-2700.58667.

10. Steele WR, Schreiber GB, Guiltinan A, Nass C, Glynn SA, Wright DJ, et al. The role of altruistic behavior, empathetic concern, and social responsibility motivation in blood donation behavior. Transfus. 2008;48(1):43-54. doi: https://doi.org/10.1111/j.1537-2995.2007.01481.x.

11. Hupfer ME, Taylor DW, Letwin JA. Understanding Canadian student motivations and beliefs about giving blood. Transfus. 2005;45(2):149-161. doi: https://doi.org/ 10.1111/j.1537-2995.2004.03374.x.

12. Schreiber GB, Schlumpf KS, Glynn SA, Wright DJ, Tu Y, King MR, et al. Convenience, the bane of our existence, and other barriers to donating. Transfus. 2006;46(4):545553. doi: https://doi.org/10.1111/j.1537-2995.2006. 00757.x.

13. Madrona DP, Herrera MD, Jiménez DP, Giraldo SG, Campos RR. Women as whole blood donors: offers, donations and deferrals in the province of Huelva, southwestern Spain. Blood Transfus. 2014;12(1):s11-s20. doi:10.2450/2012.0117-12.

14. Uma S, Arun R, Arumugam P. The knowledge, attitude and practice towards blood donation among voluntary blood donors in Chennai, India. J Clin Diagn Res. 2013;7(6):1043-1046. doi:10.7860/JCDR/2013/4851.3033.

15. Shenga N, Thankappan K, Kartha C, Pal R. Analyzing socio demographic factors amongst blood donors. J Emerg
Trauma Shock. 2010;3(1):21-25. doi: 10.4103/09742700.58667

16. Sharma R, Madan N, Venkatesh S, Ichhpujani RL, Lal S. Factors influencing blood donations and the rational use of blood_J Commun Dis. 2010;42(3):185-190.

17. Marantidou O, Loukopoulou L, Zervou E, Martinis G, Egglezou A, Fountouli P, et al. Factors that motivate and hinder blood donation in Greece. Transfus Med. 2007;17(6):443-450. doi: https://dx.doi.org/10.1111\%2Fj. 1365-3148.2007.00797.x.

18. Sadler A, Shi L, Bethge S, Mühlbacher A. Incentives for Blood Donation: A Discrete Choice Experiment to Analyze Extrinsic Motivation. Transfus Med Hemother. 2018;45(2):116-124. doi:10.1159/000481142.

19. Sümnig A, Feig M, Greinacher A, Thiele T. The role of social media for blood donor motivation and recruitment. Transfus. 2018;58(10):2257-2259. doi: 10.1111/trf.14823. Epub 2018 Sep 10.

20. Mohammed S, Essel HB. Motivational factors for blood donation, potential barriers, and knowledge about blood donation in first-time and repeat blood donors. BMC Hematol. 2018;18(1):36. doi:10.1186/s12878-018-0130-3 .

21. Asamoah-Akuoko L, Hassall OW, Bates I, Ullum H. Blood donors' perceptions, motivators, and deterrents in Sub-Saharan Africa-A scoping review of evidence. Brit J Haem. 2017;177(6):864-977. doi: 10.1111/bjh.14588.

22. Ahmad Farooqui I, Pore PD. Motivating factors among blood donors in pune, India. Indian J Community Med. 2018; 43(2):130-131. doi: 10.4103/ijcm.IJCM_265_17.

23. Muthivhi TN, Olmsted MG, Park H, Sha M, Raju V, Mokoena T, et al. Motivators and deterrents to blood donation among Black South Africans: a qualitative analysis of focus group data. Transfus Med. 2015;25(4):249-258. doi: 10.1111/tme.12218. Epub 2015 Jun 23.

24. Bednall TC, Bove LL. Donating blood: a meta-analytic review of self-reported motivators and deterrents. Transfus Med Rev. 2011;25(4):317-34. doi: 10.1016/j.tmrv.2011.04. 005. Epub 2011 Jun 8.

\section{How to cite this article?}

Joseph S.E., Bose B.M., Joseph E., Poothiode U. Motivating factors, potential deterrents and perceived physical impacts of blood donation on donors. Trop J Path Micro 2019;5(12): 997-1002.doi:10.17511/ jopm.2019.i12.05 